\title{
Ultrasonic investigations of some bismuth borate glasses doped with $\mathrm{Al}_{2} \mathbf{O}_{3}$
}

\author{
YASSER B SADDEEK ${ }^{1, *}$, MOENIS A AZOOZ ${ }^{2}$ and AMR BAKR SADDEK ${ }^{3}$ \\ ${ }^{1}$ Faculty of Science, Physics Department, Al-Azhar University, Assiut, Egypt \\ ${ }^{2}$ Glass Research Department, National Research Center, Dokki, Cairo, Egypt \\ ${ }^{3}$ Faculty of Engineering, Civil Engineering Department, Beni-Suef University, Beni-Suef, Egypt
}

MS received 3 August 2013; revised 27 February 2014

\begin{abstract}
The velocities of longitudinal and transverse ultrasonic waves in different compositions of $5 \mathrm{Al}_{2} \mathrm{O}_{3}-$ $29 \mathrm{Na}_{2} \mathrm{O}-(66-x) \mathrm{B}_{2} \mathrm{O}_{3}-x \mathrm{Bi}_{2} \mathrm{O}_{3}$ glass system were measured at $4 \mathrm{MHz}$ at room temperature using the pulse-echo technique. The velocity data were used to determine the elastic moduli and the dimensionality of the studied glasses. The observed changes in the elastic moduli of the glasses were related to the modifier role of $\mathrm{Bi}_{2} \mathrm{O}_{3}$ content. The results revealed that the density increased with increasing $\mathrm{Bi}_{2} \mathrm{O}_{3}$ content, which was attributed to the increase in the compactness and packing of the glass network. The ultrasonic data were analysed in terms of creation of new bonds of $\mathrm{Bi}_{2} \mathrm{O}_{3}$ attached to the structural units of the borate network. The new bonds decreased the average crosslink density and the number of network bonds per unit volume along with a weakening of the different modes of vibrations, which in its turn decreased the ultrasonic velocity. Quantitative analysis was carried out using Makishima-Mackenzie model in order to obtain more information about the rigidity of these glasses.
\end{abstract}

Keywords. Bismuth borate glasses; elastic moduli; Makishima-Mackenzie model.

\section{Introduction}

The well understanding of the structure-properties (optical, thermodynamic and mechanical) relationship of the physical processes occurring simultaneously is a key problem in materials science. In contrast to the crystalline solids, whose physical properties and structure are essentially understood, there remain some considerable theoretical and experimental difficulties for amorphous solids, including bismuth boratebased glasses. Due to the hygroscopic nature of pure borate glasses, many studies were conducted to improve their chemical resistance. For example, doping boron oxide with sodium oxide leads to stable ionic glasses, with compositions covering a very broad and continuous range. ${ }^{1}$ Moreover, bismuth is the heaviest element, have a stable and nonradiative nucleus. ${ }^{2}$ Bismuth oxide is a conditional network former because of the small field strength of $\mathrm{Bi}^{3+}$ ion. $\mathrm{Bi}_{2} \mathrm{O}_{3}$ in combination with $\mathrm{B}_{2} \mathrm{O}_{3}$ forms glasses in a relatively large composition range. ${ }^{3}$

Recently, bismuth borate glasses have become technologically important materials, primarily because of their relatively large thermal expansion coefficients, low optical dispersions and low glass transition temperatures. ${ }^{4-6}$ Bismuth borate glasses have been extensively investigated due to their transparency in a wide spectral range from UV to IR, which makes them suitable for the fabrication of optical

\footnotetext{
*Author for correspondence (ysaddeek@gmail.com)
}

fibres, detection, sensing and laser technologies (laser host glasses). ${ }^{7-10}$

On the other hand, the research in the field of glasses using ultrasonic parameters such as velocity and attenuation as a function of composition, besides the density and molar volume, has been carried out for many years. ${ }^{11-13}$ In the study of glass samples, the ultrasonic wave propagation is greatly influenced by the density of the sample.

Based on the aforementioned aspects, the present work is aimed to progress and is following the previous FTIR studies $^{8,14-23}$ on the structural modifications that take place in the glass network of bismuth borate glasses modified by $\mathrm{Al}_{2} \mathrm{O}_{3}$ and in terms of the elastic moduli. According to these studies, the rigidity of bismuth borate glasses is lower than that of borosilicate glasses. So, addition of $\mathrm{Al}_{2} \mathrm{O}_{3}$ will stiffen the structure of the glasses and raise its resistance to compression. Also, addition of any quantity of $\mathrm{Al}_{2} \mathrm{O}_{3}$ is known to reduce the crystallization region of the glass significantly on cooling, even in the case of low alkali content.

\section{Experimental}

Glass samples of the vitreous system $5 \mathrm{Al}_{2} \mathrm{O}_{3}-29 \mathrm{Na}_{2} \mathrm{O}-$ $(66-x) \mathrm{B}_{2} \mathrm{O}_{3}-x \mathrm{Bi}_{2} \mathrm{O}_{3}$ with $(0 \leq x \leq 20 \mathrm{~mol} \%)$ have been prepared by the well-known melt quench technique. Appropriate amounts of Analar grade $\mathrm{Bi}_{2} \mathrm{O}_{3}, \mathrm{H}_{3} \mathrm{BO}_{3}, \mathrm{Na}_{2} \mathrm{CO}_{3}$ and $\mathrm{Al}_{2} \mathrm{O}_{3}$ were mixed thoroughly by grinding the mixture repeatedly to obtain a fine powder. Melts of aforesaid samples with different compositions were obtained in electrically 
heated furnace at $1050^{\circ} \mathrm{C}$ to ensure homogeneity. Annealing process in copper mould up to room temperature was followed in the melting process, and the obtained samples (cylindrical shape) were ground and polished. The obtained glasses were lapped and two opposite sides were polished to be suitable in the ultrasonic velocity measurements. Non-parallellism of the two opposite side faces was less than $0.01^{\circ}$. X-ray diffraction patterns were recorded using a Philips X-ray diffractometer PW/1710 with Ni-filtered, $\mathrm{Cu}-\mathrm{K}_{\alpha}$ radiation $(\lambda=1.542 \AA)$ powered at $40 \mathrm{kV}$ and $30 \mathrm{~mA}$. The patterns (not shown) revealed a broad hump that characterized the amorphous materials and did not reveal any discrete or sharp peaks. The density was measured by Archimedes principle using toluene as the immersion liquid. The transition temperature $\left(T_{\mathrm{g}}\right)$ of these glasses was measured using standard Shimadzu differential thermal analyzer system (DTA 50). The 15-mg powdered glass samples were placed in a platinum crucible and were examined up to $800^{\circ} \mathrm{C}$ in Argon medium. The powdered alumina was used as a reference material. The accuracy in the measurement of $T_{\mathrm{g}}$ was $\pm 2 \mathrm{~K}$. The ultrasonic velocities, longitudinal $\left(v_{\mathrm{L}}\right)$ and shear $\left(v_{\mathrm{T}}\right)$, at room temperature $(\sim 300 \mathrm{~K})$ were obtained using the pulse-echo method. In this method, $\mathrm{x}$-cut and $\mathrm{y}$-cut transducers (Karl Deutsch), operated at a fundamental frequency of $4 \mathrm{MHz}$ along with a digital ultrasonic flaw detector (Karl Deutsch echograph model 1085) were used. The uncertainty in the measurement of the ultrasonic velocity was $\pm 10 \mathrm{~m} \mathrm{~s}^{-1}$. The two velocities, besides the density, were utilized to determine two independent second-order elastic constants (SOECs), $L$ and $G$. For pure longitudinal waves $L=\rho v_{\mathrm{L}}^{2}$, and for pure transverse waves $G=\rho v_{\mathrm{T}}^{2}$. The bulk modulus $\left(K_{\mathrm{e}}\right)$, Young's modulus $(Y)$, the Debye temperature $\left(\theta_{\mathrm{D}}\right)$ and Poisson's ratio $(\sigma)$ may be determined from the determined elastic constants, $L$ and $G$, using the standard relations:

$$
\begin{aligned}
& \sigma=1 / 2-G / 2(L-G), \\
& Y=2(1+\sigma) G, \\
& K_{\mathrm{e}}=L-4 / 3 G, \\
& \theta_{\mathrm{D}}=(h / k) v_{\mathrm{D}}\left[\frac{3 q \rho N_{\mathrm{A}}}{4 \pi M}\right]^{1 / 3},
\end{aligned}
$$

where $v_{\mathrm{D}}$ is the mean ultrasonic velocity given by $\left(\frac{1}{3}\left(\frac{1}{v_{\mathrm{L}}^{3}}+\frac{2}{v_{\mathrm{T}}^{3}}\right)\right)^{-1 / 3}, h$ the Planck's constant, $N_{\mathrm{A}}$ the Avogadro's number and $k$ the Boltzmann's constant. The uncertainty in the measurement of the elastic moduli is \pm 0.15 $\mathrm{GPa}$.

\section{Results and discussion}

It is known that $\mathrm{B}_{2} \mathrm{O}_{3}$ is a laminar network consisting of boron atoms 3 -fold co-ordinated with oxygen. Modification of $\mathrm{B}_{2} \mathrm{O}_{3}$ by an alkali oxide creates additional oxygen by the conversion of $\mathrm{BO}_{3}$ into 4-fold $\mathrm{BO}_{4}$. The included four oxygens in the network, which function as bridging oxygens, are responsible for increasing the connectivity of the glass network. ${ }^{1}$ The studies were conducted on simple alkali borate-based glasses ${ }^{12,13}$ and showed that the conversion of $\mathrm{BO}_{3}$ into $\mathrm{BO}_{4}$ or $N_{4}$ (ratio of $\mathrm{BO}_{4}$ to $\mathrm{BO}_{3}$ ) proceeded till a varied ratio, for example $33 \mathrm{~mol} \%$ for $\mathrm{Na}_{2} \mathrm{O}$ and $30 \mathrm{~mol} \%$ for $\mathrm{K}_{2} \mathrm{O}$. Beyond this ratio, $\mathrm{BO}_{4}$ was broken and converted into $\mathrm{BO}_{3}$. In quaternary borate-based glasses, the scene is complicated ${ }^{8,14-22}$ because several units affect this conversion and the ratio will be essentially different. Bismuth borate glasses are interesting systems to study because the glass phase can be formed over a wide concentration. Moreover, $\mathrm{Bi}_{2} \mathrm{O}_{3}$ can enter the glass network both as a network modifier and also as a network former. It is suggested that the addition of $\mathrm{Bi}_{2} \mathrm{O}_{3}$ to borate networks results in the formation of $\mathrm{Bi}-\mathrm{O}-\mathrm{Bi}$ bonds, leading to a dramatic improvement in the chemical durability and thermal stability of the borate glasses. ${ }^{9}$ On the other hand, the presence of the $\left[\mathrm{AlO}_{4}\right]^{4-}$ tetrahedra of $\mathrm{Al}_{2} \mathrm{O}_{3}$ in borate-based glasses causes the boron to remain trico-ordinated and, consequently, to a certain extent, helps to maintain the constancy of the glass structure. In boroaluminate glasses containing alkaline-earth modifier ions, $\mathrm{B}^{3+}$ and $\mathrm{Al}^{3+}$ compete for tetrahedral sites, with most going to $\mathrm{Al}^{3+}$. Substitution of $\mathrm{Al}_{2} \mathrm{O}_{3}$ for $\mathrm{B}_{2} \mathrm{O}_{3}$ replaces $\mathrm{BO}_{4}$ structural unit by $\mathrm{AlO}_{4}$ tetrahedra and the alkali ions, in this case, are bonded to $\mathrm{AlO}_{4}$ tetrahedra. Such a substitution causes a decrease in the ionic conductivity and, consequently, the supersonic velocity. ${ }^{24,25}$

Table 1 and figure 1 show the variation of both density and molar volume for all glasses as function of the $\mathrm{Bi}_{2} \mathrm{O}_{3}$ content. It was reported earlier that the density of pure $\mathrm{B}_{2} \mathrm{O}_{3}$ glass is $1832 \mathrm{~kg}^{3} \mathrm{~m}^{-3} \cdot{ }^{26}$ The results showed that the density of bismuth borate glass was increased up to the investigated level of $20 \mathrm{~mol} \% \mathrm{Bi}_{2} \mathrm{O}_{3}$ from 2203 to $3975 \mathrm{~kg} \mathrm{~m}^{-3}$. From a microscopic perspective, the increase in density of glasses is probably due to increase in the number of non-bridging oxygen (NBO) atoms. The increase may be attributed to the intersubstitution of $\mathrm{B}_{2} \mathrm{O}_{3}(69.6 \mathrm{~g})$ by $\mathrm{Bi}_{2} \mathrm{O}_{3}$ molecules, which have a higher molecular weight $(465.96 \mathrm{~g})$, while the ratio of the other concentrations to each other still remains constant. The increase in density is also consistent with a previous work on the bismuth borate glass system. ${ }^{16-19,21}$ Recent studies ${ }^{8,15-22}$ have shown that progressive addition of $\mathrm{Bi}_{2} \mathrm{O}_{3}$ introduces extra-networkformer units. Such units change the crosslink density and the co-ordination numbers of $\mathrm{Bi}^{3+}$ ions by the creation of $\mathrm{Bi}-\mathrm{O}-\mathrm{B}$ bonds that condense the structure more. On the other hand, the increase in the molar volume means an increase in the bond length or interatomic spacing between the atoms and may be attributed to the difference in the radius of $\mathrm{Bi}^{+6}(0.102 \mathrm{~nm})$, which is much greater than that of $\mathrm{B}^{+3}(0.020 \mathrm{~nm})$, or to the creation of NBOs, which will break the bonds of the sodium borate host glass, and then the spaces in the network will increase. ${ }^{10}$

Recent spectroscopic studies on heavy metal oxides such as $\mathrm{Bi}_{2} \mathrm{O}_{3}$ - or $\mathrm{PbO}$-based borate glasses ${ }^{8-10,15-22,26}$ have 
Table 1. Composition, density $(\rho)$, molar volume $\left(V_{\mathrm{m}}\right)$, glass transition temperature $\left(T_{\mathrm{g}}\right)$, elastic moduli (Young's modulus: $Y$, the bulk modulus: $K_{\mathrm{e}}$, micro-hardness: $H$ ), Debye temperature $\left(q_{\mathrm{D}}\right)$, Poission's ratio $(\sigma)$, ratios $4 G / K_{\mathrm{e}}, G / C_{12}$, packing density $\left(V_{\mathrm{to}}\right)$, dissociation energy $\left(D_{\mathrm{to}}\right)$, Young's modulus $\left(E_{\mathrm{m}}\right)$ and the bulk modulus $\left(K_{\mathrm{m}}\right)$ according to Makishima-Mackenzie model of the quaternary glass system $5 \mathrm{Al}_{2} \mathrm{O}_{3}-29 \mathrm{Na}_{2} \mathrm{O}-(66-x) \mathrm{B}_{2} \mathrm{O}_{3}-x \mathrm{Bi}_{2} \mathrm{O}_{3}$.

\begin{tabular}{lcccccccccccccc}
\hline $\begin{array}{l}\mathrm{Bi}_{2} \mathrm{O}_{3} \\
(\mathrm{~mol} \%)\end{array}$ & $\begin{array}{c}\rho \\
\left(\mathrm{kg} \mathrm{m}^{-3}\right)\end{array}$ & $\begin{array}{c}V_{\mathrm{m}} \times 10^{-6} \\
\left(\mathrm{~m}^{3} \mathrm{~mol}^{-1}\right)\end{array}$ & $\begin{array}{c}T_{\mathrm{g}} \\
\left({ }^{\circ} \mathrm{C}\right)\end{array}$ & $\begin{array}{c}K_{\mathrm{e}} \\
(\mathrm{GPa})\end{array}$ & $\begin{array}{c}Y \\
(\mathrm{GPa})\end{array}$ & $\begin{array}{c}H \\
(\mathrm{GPa})\end{array}$ & $\begin{array}{c}\theta_{\mathrm{D}} \\
(K)\end{array}$ & $\sigma$ & $4 G / K_{\mathrm{e}}$ & $G / C_{12}$ & $V_{\mathrm{to}}$ & $D_{\mathrm{to}}$ & $E_{\mathrm{m}}$ & $K_{\mathrm{m}}$ \\
\hline 0 & 2203 & 31.33 & 480 & 49.5 & 63.6 & 3.46 & 489 & 0.29 & 1.99 & 0.75 & 0.58 & 41.4 & 48.6 & 28.5 \\
5 & 2644 & 33.60 & 466 & 54.9 & 74.6 & 4.33 & 474 & 0.27 & 2.15 & 0.84 & 0.56 & 42.1 & 46.7 & 25.9 \\
10 & 3229 & 33.65 & 455 & 67.6 & 92.7 & 5.55 & 475 & 0.27 & 2.16 & 0.84 & 0.56 & 42.8 & 48.1 & 27.02 \\
15 & 3479 & 36.93 & 449 & 72.3 & 97.3 & 5.60 & 457 & 0.28 & 2.11 & 0.81 & 0.52 & 43.5 & 45.2 & 23.5 \\
20 & 3975 & 37.31 & 444 & 82.2 & 108.8 & 6.37 & 450 & 0.28 & 2.07 & 0.79 & 0.52 & 44.2 & 46.1 & 24 \\
\hline
\end{tabular}

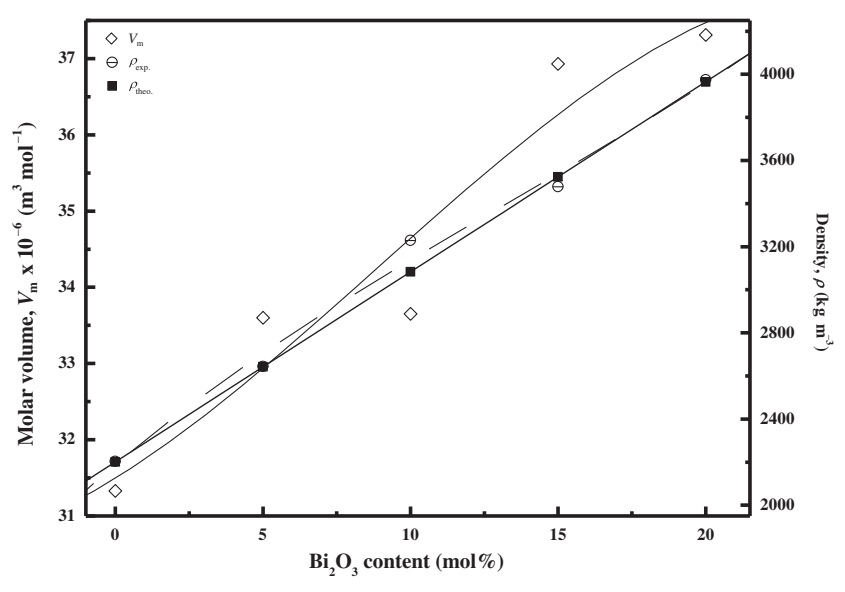

Figure 1. Density $\rho$ and molar volume $V_{\mathrm{m}}$ of the quaternary glass system $5 \mathrm{Al}_{2} \mathrm{O}_{3}-29 \mathrm{Na}_{2} \mathrm{O}-(66-x) \mathrm{B}_{2} \mathrm{O}_{3}-x$ with $0 \leq x \leq 20$ mol\%. Open symbols represent the experimental values and the closed ones are calculated values. Lines are fitting plots of the data. The random error in the density values is $\pm 1 \%$, whereas the error limit in $V_{\mathrm{m}}$ values is estimated as $\pm 0.9 \%$.

shown the formation of $\mathrm{BO}_{4}$ units due to the introduction of $\mathrm{Bi}_{2} \mathrm{O}_{3}$ in the borate matrix. A compensation of the negative charge on the $\mathrm{BO}_{4}$ tetrahedra would be verified from positively charged structural defects in the $\mathrm{Bi}_{2} \mathrm{O}_{3}$ network or from one of the positive charges of $\mathrm{Na}^{2+}$ cation for each $\mathrm{BO}_{4}$ tetrahedron. Thus, in the glasses studied, $\mathrm{BO}_{4}$ units can be linked to $\mathrm{Na}^{2+}$ cations and they replace those compensated with positive sites in the $\mathrm{Bi}_{2} \mathrm{O}_{3}$ network. The increase in density (figure 1) reveals that the former type of $\mathrm{BiO}_{6}$ unit is denser than the $\mathrm{BO}_{4}$ or $\mathrm{BO}_{3}$ structural unit.

It is clear that, by increasing $\mathrm{Bi}_{2} \mathrm{O}_{3}$, the molar volume increases, which is similar to the variation density that occurs with increasing $\mathrm{Bi}_{2} \mathrm{O}_{3}$ content. The $\mathrm{Bi}^{3+}$ ions may enter the glass network interstitially; hence, some network $\mathrm{B}-\mathrm{O}-\mathrm{B}$ bonds were broken and replaced by ionic bonds between $\mathrm{Bi}^{3+}$ ions and singly bonded oxygen atoms. Therefore, if one assumed that the only effect of adding Bi cations was to break down the network $\mathrm{B}-\mathrm{O}-\mathrm{B}$ bonds, then an increase in the molar volume with $\mathrm{Bi}_{2} \mathrm{O}_{3}$ content would be expected for the entire range of vitreous glass system studied.
The increase of density, as shown in figure 1, can be explained by the suggestion that each component contributes to the density with a specific factor. In such a case, the density can be given as

$$
D=f_{\mathrm{B}} C_{\mathrm{B}}+f_{\mathrm{Bi}} C_{\mathrm{Bi}}+f_{\mathrm{Na}} C_{\mathrm{Na}}+f_{\mathrm{Al}} C_{\mathrm{Al}},
$$

where $f_{\mathrm{B}}, f_{\mathrm{Bi}}, f_{\mathrm{Na}}$ and $f_{\mathrm{Al}}$ are, respectively, the factors with which $\mathrm{B}_{2} \mathrm{O}_{3}, \mathrm{Bi}_{2} \mathrm{O}_{3}, \mathrm{Na}_{2} \mathrm{O}$ and $\mathrm{Al}_{2} \mathrm{O}_{3}$ contribute to the density and $C_{\mathrm{B}}, C_{\mathrm{Bi}}, C_{\mathrm{Na}}$ and $C_{\mathrm{Al}}$ the molar fraction of those oxides, respectively. Starting with $f_{\mathrm{B}}=1.823 \mathrm{~g} \mathrm{~cm}^{-3}$ (the density of vitreous $\mathrm{B}_{2} \mathrm{O}_{3}{ }^{26}$ ) and solving (5) for different values of $D$ lead to $f_{\mathrm{Bi}}=10.64 \mathrm{~g} \mathrm{~cm}^{-3}$, $f_{\mathrm{Na}}=2.5 \mathrm{~g} \mathrm{~cm}^{-3}$ and $f_{\mathrm{Al}}=5.45 \mathrm{~g} \mathrm{~cm}^{-3}$. The filled symbol in figure 1 represents calculated densities obtained from (5) and the predicted factors. It appears that the greatest contribution to density is from $\mathrm{Bi}_{2} \mathrm{O}_{3}$ units.

The glass transition temperature $\left(T_{\mathrm{g}}\right)$ is an important thermal parameter used in exploring the different criteria of the thermal stability of the bismuth borate glass structure. ${ }^{9}$ The glasses have loose-packed structure, are thermally unstable and have declining $T_{\mathrm{g}}$ values. In the glasses studied, the values of $T_{\mathrm{g}}$ decreased from 480 to $444^{\circ} \mathrm{C}$ with the increase of $\mathrm{Bi}_{2} \mathrm{O}_{3}$ content (table 1). The increase in the molar volume resulted in a decrease in $T_{\mathrm{g}}$ as shown in figure 2. According to the recent spectroscopic studies on bismuth borate glasses, as the $\mathrm{Bi}_{2} \mathrm{O}_{3}$ content increases the NBOs increase and the structure will be less crosslinked. This behaviour may be due to the transformation of $\mathrm{BO}_{4}$ to $\mathrm{BO}_{3}$ (effect of $\mathrm{BiO}_{6}$ and $\mathrm{AlO}_{6}$ ). Also, this decrease may be due to the disruption of the network structure by introducing weaker bonds, as a result of changing the kind of the former from $\mathrm{B}_{2} \mathrm{O}_{3}$ to $\mathrm{Bi}_{2} \mathrm{O}_{3} .{ }^{9}, 10,15-22,26$

In a study of the elastic constants of materials using ultrasonic methods, the main point to note is the propagation of the ultrasonic wave velocity and the density. From the data for the ultrasonic wave propagation velocity mode, the series of elastic constants can be determined. Due to the elastic constants of this second-order difference of the total energy of the strain, the constant values can be used to explore the bonding forces between the atoms in the material. Typically, when the material undergoes a phase change, the value of the elastic constants will also be changed. ${ }^{27,28}$ Table 1 presents the values of the elastic moduli. Now the relation between 


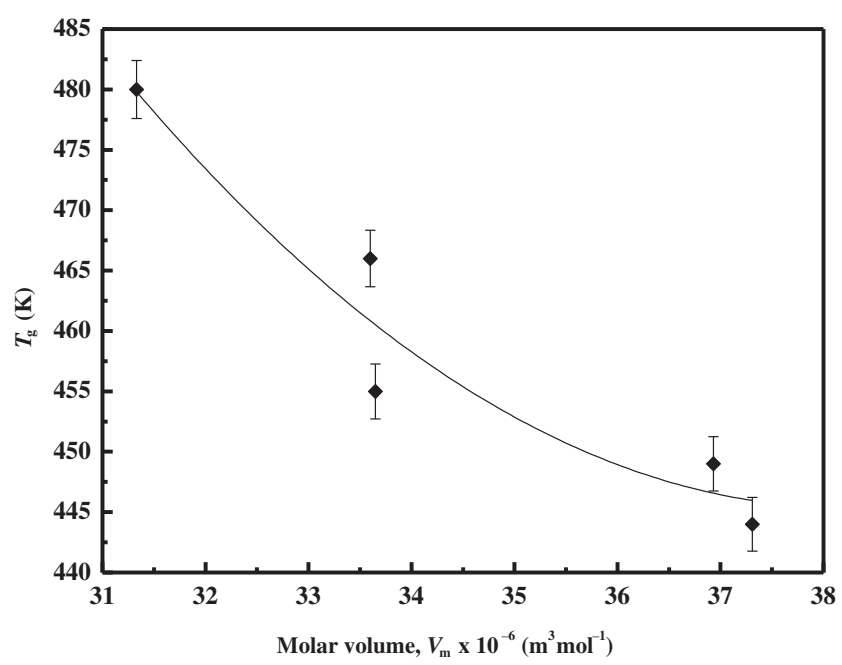

Figure 2. Dependence of the glass transition temperature on the molar volume for the glass system $5 \mathrm{Al}_{2} \mathrm{O}_{3}-29 \mathrm{Na}_{2} \mathrm{O}-(66-x)$ $\mathrm{B}_{2} \mathrm{O}_{3}-x$ with $0 \leq x \leq 20 \mathrm{~mol} \%$.

the dimensionality and the structure of these glasses will be discussed based on some relations reported elsewhere. ${ }^{21,27}$ These relations are: the $d$-value or $4 G / K_{\mathrm{e}}$, which is defined as the degree of the dimensionality of amorphous structure, and the ratio $G / C_{12}$, which is considered as an indicator of the character of the force field, $G / C_{12}=1$ when the type of the forces is central and $G / C_{12} \neq 1$ if the type of forces is non-central, $C_{12}=L-2 G$. The listed data (table 1) describes two-dimensional structure, as the $d$-value is about 2, while $d=3$ characterize the three-dimensional structure and the type of the predominant forces is not central as $G / C_{12}$ is less than 1 . It was found that as the ratio of $G / C_{12}$ approaches to unity, the central force field may reduce the fraction of the broken bonds in the glass structure. In the investigated glasses, as the bismuth content increased, it was noted that the two ratios describing the dimensionality of the amorphous structure tended to decrease as listed in table 1. Accordingly, the structure of the glasses studied, have been described as two dimensional or laminar network characterizing alkali bismuth borate glasses and the predominant forces are non-central, which result from the ionic-overlapping and covalent bonding. $\mathrm{As}^{\mathrm{BiO}_{6}}$, which act as a network modifier, converts $\mathrm{BO}_{4}$ into $\mathrm{BO}_{3}$ and creates NBOs, the dimensionality decreased as a direct result from the decrease of the dissociation energy of the studied glasses, as the bond strength of $\mathrm{Bi}-\mathrm{O}$ is lower than that of B-O. ${ }^{16-20}$

As mentioned before, the addition of $\mathrm{Bi}_{2} \mathrm{O}_{3}$ in glass interstices causes a breaking in the network $\mathrm{B}-\mathrm{O}-\mathrm{B}$ bonds, and an increase in the molar volume. Thus, the glass structure will be less compacted. As a consequence, and as shown in figure 3 , a decrease of the ultrasonic velocities and also the Debye temperature (table 1), which depends directly on the mean ultrasonic velocity with an increase in the $\mathrm{Bi}_{2} \mathrm{O}_{3}$ concentration, has been observed. Debye temperature $\theta_{\mathrm{D}}$ is the

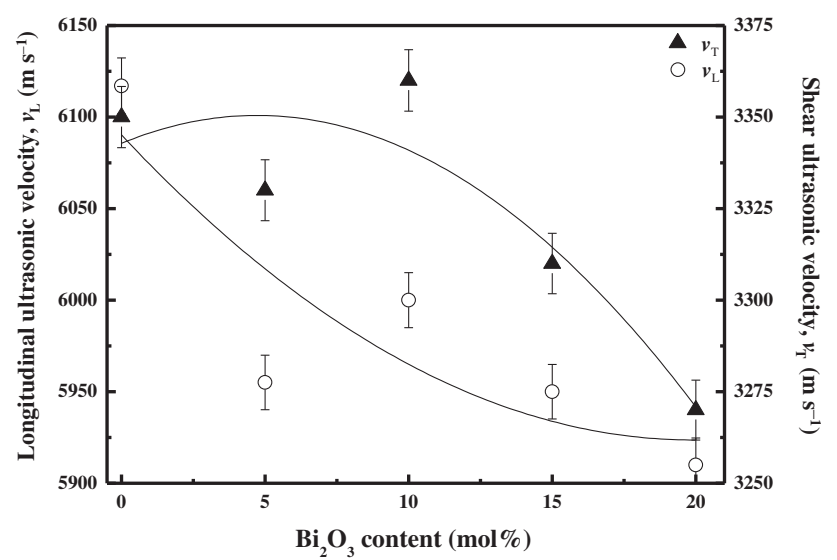

Figure 3. Dependence of the longitudinal and shear ultrasonic velocities $v_{\mathrm{L}}$ and $v_{\mathrm{T}}, 5 \mathrm{Al}_{2} \mathrm{O}_{3}-29 \mathrm{Na}_{2} \mathrm{O}-(66-x) \mathrm{B}_{2} \mathrm{O}_{3}-x$ with $0 \leq x \leq 20 \mathrm{~mol} \%$, on the $\mathrm{Bi}_{2} \mathrm{O}_{3}$ content. Lines are fitting plots of the data. The uncertainty in the measurement of $v_{\mathrm{L}}$ is $\pm 10 \mathrm{~m} \mathrm{~s}^{-1}$ and the error limit in $\theta_{\mathrm{D}}$ is estimated as $\pm 1 \%$.

temperature at which all the low frequency 'lattice' vibrational modes are excited. It plays an important role in solid materials in the determination of elastic moduli and atomic vibrations. The observed decrease in the Debye temperature, as listed in table 1, supports the claim that addition of $\mathrm{Bi}_{2} \mathrm{O}_{3}$ creates NBOs and causes loose packing in the glass structure and also a reduction in the vibrations of the lattice, as observed earlier. ${ }^{14}$ This discussion supported the network modifier role of $\mathrm{Bi}_{2} \mathrm{O}_{3}$ in the velocities.

Poisson's ratio $(\sigma)$ is the ratio of the transverse and linear strains for a linear stress and depends on both the dimensionality of the structure and crosslink density. A threedimensional network structure with high crosslink density has Poisson's ratio in the order of 0.1 to 0.2. A twodimensional structure having low crosslink density has a value in the range between 0.3 and 0.5 , with the concentration of bonds resisting the transverse deformation. As the $\mathrm{Bi}_{2} \mathrm{O}_{3}$ content increases, there is a conversion of $\mathrm{BO}_{4}$ into $\mathrm{BO}_{3}$ due to the effect of $\mathrm{BiO}_{6}$ structural units, which leads to the formation of NBOs. In the present system, Poisson's ratio is almost constant (changes from 0.27 to 0.29 ) with almost constant crosslink density (changes from 1.6 to 1.7), when the $\mathrm{Bi}_{2} \mathrm{O}_{3}$ content is increased as $0 \leq x \leq 20$.

The elastic moduli of isotropic materials such as glasses are informative about the structure of these non-crystalline solids, as they are directly related to the inter-atomic forces and potentials. The changes in the nature of the chemical bond and the bond strength in the glass structure are normally incorporated in Young's modulus, which has the ability to determine the fracture behaviour involved in the glasses. On the other hand, the bulk modulus is more sensitive in exploring the changes in the crosslink density and the bond stretching force constant. In general, the elastic moduli increase when the density or the ultrasonic velocity increases, depending on what plays the major role in controlling the 
elastic moduli. It is clear from the above results that the density plays a dominant role in determining the bulk modulus rather than the type of bonding in the network (effect of $\mathrm{Bi}_{2} \mathrm{O}_{3}$ addition).

The bulk modulus $K_{\mathrm{e}}$ can be related to the mean atomic volume per atom $\left(V_{\mathrm{a}}\right)$ by the relation $K_{\mathrm{e}} V_{\mathrm{a}}^{\mathrm{m}}=C$, where $C$ is a constant. ${ }^{21}$ It was found that $m$ for oxide glasses is 4 , and the variation of $m$ in the bulk modulus-volume relationship is determined by the nature of the bonding, and the co-ordination polyhedra. When the volume change occurs without change in the nature of the bonding or change in the co-ordination polyhedra, $\log \left(K_{\mathrm{e}}\right)-\log \left(V_{\mathrm{a}}\right)$ plots generally are linear. The results of this relation for the glasses studied indicate an increase in $\left(K_{\mathrm{e}}\right)$ and $\left(V_{\mathrm{a}}\right)$, i.e., the density plays the main role in determining the bulk modulus. Therefore, the relation will be linear and $m=2$.

The compositional dependence of the bulk modulus may be discussed in terms of the glass structure, as the addition of $\mathrm{Bi}_{2} \mathrm{O}_{3}$ results in an increase of density (the bulk modulus increased). The bulk modulus of a covalent network is determined by the bond density (number of bonds in a unit volume), and by the stretching force constant. The force constant is related to the cation field strength of the modifier, i.e., low field strength cations polarize their environment weakly and decrease the ion-dipole interaction. The decrease in the cation field strength will decrease the packing density due to the variation of the network around such a cation.

It is important to demonstrate the applicability of Makishima-Mackenzie's theory ${ }^{29-31}$ for the present glasses. Makishima-Mackenzie suggested that the elastic moduli are function of both the packing density (ionic radii of elements) and the average strength (dissociation energy) of the chemical bonds in the glass. The details of the computation of the elastic moduli for the borate glasses, according to this model, were explained elsewhere. ${ }^{12,13}$ According to Inaba et $a l,{ }^{32}$ the values of the packing factors for $\mathrm{Na}_{2} \mathrm{O}, \mathrm{Al}_{2} \mathrm{O}_{3}$, and $\mathrm{Bi}_{2} \mathrm{O}_{3}$ are considered to be $12.3 \times 10^{-6}, 21.5 \times 10^{-6}$ and $26.1 \times 10^{-6} \mathrm{~m}^{3} \mathrm{~mol}^{-1}$, respectively, while the dissociation energy for these oxides are $31.9 \times 10^{6}, 119.2 \times 10^{6}$ and $31.6 \times 10^{6} \mathrm{~kJ} \mathrm{~m}^{-3}$, respectively. The dissociation energy of $\mathrm{B}_{2} \mathrm{O}_{3}$ has two values, $16.4 \times 10^{6}$ (co-ordination number 3 ) and $77.9 \times 10^{6} \mathrm{~kJ} \mathrm{~m}^{-3}$ (co-ordination number 4 ). ${ }^{30}$ modify the expression of the packing density to agree the computed elastic moduli fairly with the determined experimentally moduli. The values of these moduli, according to the modification of Makishima-Mackenzie model ${ }^{29,31}$ for all glass samples, are given in table 1 . Figure 4 shows the relation between the computed ${ }^{30}$ and the experimentally determined Young's modulus.

The evaluation of the elastic moduli, according to the model, reveals that the values of the elastic moduli are lower than those measured experimentally. These lower values may be attributed to the decreasing packing density and the increasing molar volume of the glass studied. Addition of $\mathrm{Bi}_{2} \mathrm{O}_{3}$ will reduce the packing density and the dissociation energy of the glasses studied. This is attributed to the decrease in the stretching force constant. Therefore, the

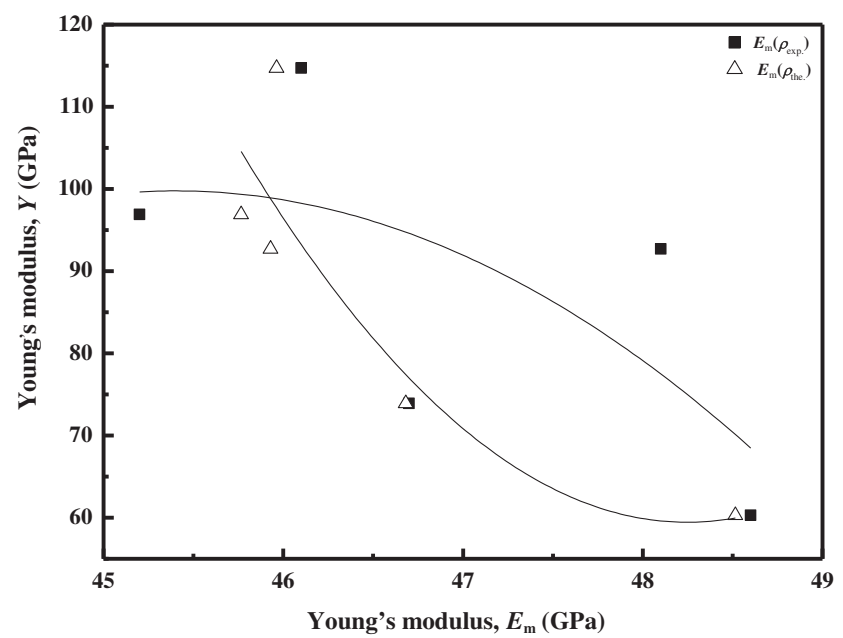

Figure 4. Agreement between the experimental and theoretically calculated values of Young's modulus of the glass system $5 \mathrm{Al}_{2} \mathrm{O}_{3}-$ $29 \mathrm{Na}_{2} \mathrm{O}-(66-x) \mathrm{B}_{2} \mathrm{O}_{3}-x$ with $0 \leq x \leq 20 \mathrm{~mol} \%$. The line is a fit to all presented data.

elastic moduli of the glass system will depend on the increase of the density.

\section{Conclusions}

The ultrasonic studies on the network structure of quaternary $\mathrm{Al}_{2} \mathrm{O}_{3}-\mathrm{Na}_{2} \mathrm{O}-\mathrm{B}_{2} \mathrm{O}_{3}-\mathrm{Bi}_{2} \mathrm{O}_{3}$ glass system revealed that the increase in the elastic constants, observed in this study, with the increase of $\mathrm{Bi}_{2} \mathrm{O}_{3}$ mol\% content was mainly due to the increase in the density. Also, the decrease in the glass transition temperature was attributed to the replacement of boron atoms by bismuth atoms. This decrease also can be attributed to the decrease of the average crosslink density and the stretching force constant. The dimensionality study of these glasses confirms the two-dimensional structure of the bismoborate glasses.

\section{References}

1. Kodama M 1991 J. Mater. Sci. 264048

2. Kaufmann E 2003 Characterization of materials, vol.1, WileyInterscience A John Wiley and Sons Publication

3. Dumbaugh W and Lapp J 1992 J. Am. Ceram. Soc. 752315

4. El-Egili K and Doweidar H 1995 Phys. Chem. Glasses 36211

5. Pan A and Ghosh A 2002 J. Mater. Res. 171941

6. Boonin K et al 2011 Procedia Eng. 8207

7. El-Shaarawy M and El-Batal F 2002 Phys. Chem. Glasses 4 247

8. Saddeek Y et al 2008 Physica B 4032399

9. Shaaban E et al 2008 J. Phys.: Condens. Matter 20155108

10. Pisarska J et al 2010 Optics Laser Techno. 42805

11. Sidkey M A et al 2002 Mater. Chem. Phys. 74222

12. Saddeek Y 2004a Mater. Chem. Phys. 83222

13. Saddeek Y 2004b Physica B 344163 
14. Saddeek Y et al 2004 Physica B 348475

15. Saddeek Y et al 2007 J. Phys. D: Appl. Phys. 404674

16. Saddeek Y et al 2010a J. Alloys Comp. 494210

17. Saddeek Y et al 2010b J. Non-Cryst. Solids 3561089

18. Saddeek Y et al 2010c Physica B 4052407

19. Saddeek Y et al 2010d Solid State Sci. 121426

20. Saddeek Y 2009 J. Alloys Comp. 46714

21. Doweidar H et al 2009 J. Non-Cryst. Solids 355348

22. Doweidar H et al 2010 J. Non-Cryst. Solids 3561452

23. Gaafar M et al 2009 J. Phys. Chem. Solids 70173
24. Stookey S 1959 Ind. Eng. Chem. 51805

25. Chryssikos G et al 1990 J. Non-Cryst. Solids 12642

26. Doweidar H et al 2001 Mater. Sci. Eng. A 301207

27. Hwa L et al 2003 Mater. Chem. Phys. 78105

28. Matori K 2013 J. Non-Cryst. Solids 36178

29. Makishima A and Mackenzie J 1973 J. Non-Cryst. Solids 1235

30. Rocherulle J et al 1989 J. Non-Cryst. Solids 108187

31. Makishima A and Mackenzie J 1975 J. Non-Cryst. Solids 17 147

32. Inaba S et al 1999 J. Am. Ceram. Soc. 823501 